\title{
CIDADANIA REGULADA E ERA VARGAS: A INTERPRETAÇÃO DE WANDERLEY GUILHERME DOS SANTOS E SUA FORTUNA CRÍTICA
}

Regulated citizenship and the Vargas Era: the interpretation of Wanderley Guilherme dos Santos and his critical fortune

La ciudadanía regulada y el periodo Vargas: la interpretación de Wanderley Guilherme dos Santos y su fortuna crítica

MARCELO SEVAYBRICKER MOREIRA ${ }^{\mathrm{I}^{*}}$ RONALDO TEODORO DOS SANTOS ${ }^{\mathrm{I} * * *}$

DOI: http://dx.doi.org/10.1590/S2178-14942020000300006

'Universidade Federal de Lavras - Lavras (MG), Brasil.

*Cientista político (marcelomoreira@ufla.br)

(D) https://orcid.org/0000-0002-3255-5532

"Universidade do Estado do Rio de Janeiro - Rio de Janeiro (RJ), Brasil.

**Cientista político (ronaldosann@gmail.com)

(D) https://orcid.org/0000-0002-0125-7700

Artigo recebido em 03 de abril de 2020 e aprovado para publicação em 15 de julho de 2020. 


\title{
RESUMO
}

Pretende-se avaliar a fortuna crítica do conceito de cidadania regulada, formulado por Wanderley Guilherme dos Santos, no intuito de apontar como esse se tornou categoria central nos esforços do pensamento político brasileiro em entender a ordem política e social posterior à Revolução de 1930. Por um lado, esse conceito permitiu identificar algumas ambiguidades da chamada Era Vargas e continuidades e rupturas entre esse período e a ditadura militar (1964-85), além de dilemas e possibilidades da redemocratização do Brasil, por outro, tendeu a idealizar certos casos nacionais de modernização, quando comparados aos países de modernização mais tardia.

PALAVRAS-CHAVE: cidadania; Revolução de 1930; Estado; classe trabalhadora; modernização conservadora.

\begin{abstract}
It is intended here to evaluate the critical fortune of the concept of regulated citizenship, formulated by Wanderley Guilherme dos Santos, in order to point out how this became a central category in the efforts of Brazilian political thought in understanding the political and social order after the Revolution 1930. On the one hand, this concept allowed to identify some ambiguities of the so-called Vargas Era and continuities and ruptures between that period and the military dictatorship (1964-85), in addition to dilemmas and possibilities for the redemocratization of Brazil, although, on the other hand, it tends to idealize certain national cases of modernization, when compared to countries of later modernization.
\end{abstract}

KEYWORDS: citizenship; Revolution of 30; State; working class; conservative modernization.

\section{RESUMEN}

Se pretende aquí evaluar la fortuna crítica del concepto de ciudadanía regulada, formulado por Wanderley Guilherme dos Santos, con el fin de señalar cómo éste se convirtió en una categoría central en los esfuerzos del pensamiento político brasileño por comprender el orden político y social posterior a la Revolución de 1930. Por un lado, este concepto permitió identificar algunas ambigüedades de la llamada Era Vargas y continuidades y rupturas entre ese período y la dictadura militar (1964-85), además de dilemas y posibilidades para la redemocratización de Brasil, aunque, por otro, tiende tendió a idealizar ciertos casos nacionales de modernización, en comparación con países de modernización posterior.

PALABRAS CLAVE: ciudadanía; Revolución de 1930; Estado; clase obrera; modernización conservadora. 


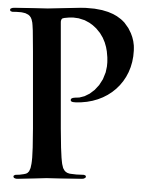

or mais de 50 anos, o carioca Wanderley Guilherme dos Santos (doravante denominado de WGS) manteve-se atuante como importante intelectual brasileiro. Formador de várias gerações de cientistas políticos, participante da última geração do Instituto Superior de Estudos Brasileiros (ISEB), fundador do Instituto Universitário de Pesquisas do Rio de Janeiro (IUPERJ), fundador e ex-presidente da Associação Nacional de Pós-Graduação em Ciências Sociais (ANPOCS), autor de mais de 30 livros, além de inúmeros artigos e capítulos de livros, WGS é um dos poucos entre seus pares que dispensa apresentação.

Não obstante sua importância, a obra de WGS carece ainda de uma análise paciente e sistemática. 0 presente trabalho não tem a pretensão de suprir essa lacuna. Ocupar-nos-emos aqui tão somente em analisar o potencial hermenêutico do conceito de cidadania regulada, elaborado por ele no livro Cidadania e justiça (1979), bem como a recepção que esse conceito teve por parte da comunidade acadêmica. Partimos da hipótese de que esse conceito tem fortes afinidades com diversas teses de interpretação do Brasil a respeito do processo descrito usualmente como modernização conservadora, processo, este, relacionado a um conjunto de transformações profundas pelas quais passou o país a partir da Revolução de 1930. Ainda que não tenhamos condição de explorar com profundidade essas afinidades, procuraremos, ao longo do trabalho, mencioná-las, a fim de indicar elementos que julgamos importantes do pensamento político brasileiro contemporâneo.

Para realizar esse objetivo, o presente trabalho está dividido em três seções. Na primeira, apresentaremos alguns traços gerais da obra de WGS para "localizar" o conceito de cidadania regulada na sua trajetória intelectual. Na segunda parte, trataremos das principais características desse conceito tanto no livro em que ele originalmente aparece quanto em obras posteriores. Na terceira seção, destacaremos as principais avaliações críticas e os usos desse conceito por outros estudiosos da realidade brasileira, bem como sua inserção nos esforços do pensamento político brasileiro em compreender a Era Vargas e a sua projeção sobre os séculos XX e XXI.

\section{BREVE INTRODUÇÃO AO PENSAMENTO DE WANDERLEY GUILHERME DOS SANTOS}

obra de WGS é, decerto, muito extensa para ser avaliada metodicamente no espaço
de um artigo. Todavia, com o propósito de introduzir o leitor nessa obra e baseados em um quadro analítico panorâmico (Moreira, 2020), dividimos seu pensamento em três fases, diferenciadas em função das temáticas e da abordagem predominante em cada uma delas. 
Uma primeira fase (1962-1963) é marcada pela sua participação no ISEB, com fortes críticas à ideologia nacional-desenvolvimentista (dominante entre a maioria dos isebianos), às posições dominantes na esquerda brasileira (principalmente aquelas vinculadas ao Partido Comunista Brasileiro) e às ideologias autoritárias, de diferentes matizes. Além de poucos artigos, o autor publicou alguns livros a essa época, tal como Introdução ao estudo das contradições sociais no Brasil (Santos, 1963), última publicação do ISEB antes do seu fechamento pelos militares, que confiscaram a obra. Anterior a esse livro e dois anos antes da deflagração do golpe, WGS escreveu um panfleto político no qual conclamava as forças populares a se unirem contra o golpe em curso no país. Quem dará o golpe no Brasil? (Santos, 1962), fascículo da coleção "Cadernos do Povo Brasileiro" (promovida pelo ISEB em associação com o Centro Popular de Cultura da União Nacional dos Estudantes), ficaria na memória nacional como uma espécie de texto visionário a respeito dos eventos que marcaram nossa história. De modo geral, os textos de WGS desse período são marcados pelo caráter crítico, fundamentado em certa leitura marxista, quanto às interpretações da realidade brasileira, e ainda não configuram uma análise eminentemente política, uma vez que as variáveis explicativas utilizadas por WGS são mais de natureza sociológica ou econômica. Nessa primeira fase, temas dominantes dos períodos subsequentes - como partidos, competição política, estabilidade democrática e políticas públicas - ainda não eram centrais.

Uma segunda fase, de 1967 a 1988, inicia-se formalmente com a publicação dos seus conhecidos artigos sobre a imaginação política brasileira que, entre textos de outros intelectuais, contribuíram para fundar o campo do pensamento político brasileiro (Lynch, 2013). Sobre os escritos dessa fase, cinco aspectos merecem ser destacados. Primeiramente, pode-se observar o esforço em ressaltar a especificidade da dinâmica política, distinguindo-a da esfera socioeconômica, pois as instituições políticas passam, destarte, a ser empregadas como variável independente dos fenômenos estudados, como é o caso paradigmático da sua tese de doutorado (defendida em Stanford, em 1969, e publicada como livro posteriormente — Santos, 1986). Nela, WGS formulou inusitada hipótese sobre o golpe de 1964, segundo a qual ele teria sido um resultado direto de uma "crise de paralisia decisória", que combinava elevada fragmentação da representação no Congresso com radicalização político-ideológica e alta rotatividade ministerial. Essa tese representava importante contraponto às análises existentes sobre o golpe, que o concebiam como decorrente de fatores econômicos e sociais, compreendendo as instituições políticas como mera variável dependente.

Outro ponto a ser destacado é que nos textos do segundo período já se constata a utilização sistemática de metodologias empíricas na investigação do fenômeno político, típicas 
da matriz de ciência política estadunidense, com a qual WGS teve contato nos anos 1960. Um conjunto de indicadores e técnicas de pesquisa estatística compõe, pois, as obras dessa fase.

0 terceiro ponto de inflexão entre a primeira e a segunda fase refere-se ao fato de WGS incorporar muitas teorias, hipóteses e conceitos da moderna ciência política, o que não ocorre nos textos da primeira fase. Tal característica não é incomum para as primeiras gerações de cientistas políticos brasileiros, e não pode ser tomada, de partida, como sinônimo de subserviência intelectual.

O quarto e último traço importante dos escritos da segunda fase é a adoção do autoritarismo como objeto de estudo privilegiado. Nesse contexto, a ordem autoritária inaugurada em 1964 procura ser compreendida à luz de nossa tradição de pensamento e prática autoritárias, particularmente do período do Estado Novo, como é o caso do livro aqui estudado - Cidadania e justiça. Há que se notar uma evidente linha de continuidade entre os textos iniciais desse período que investigavam os pensadores brasileiros denominados de "autoritários instrumentais" (Santos, 1978a) e seus textos finais, da terceira fase, que continuarão a examinar a dinâmica autoritária nacional por oposição à democrática, a ser, afinal, fundada'. 0 quinto aspecto dessa segunda fase é que, subsidiariamente e sobretudo nas obras do fim da década de 1980, o tema da transição democrática ganha saliência na obra desse autor, como é o caso do livro Poder e política (Santos, 1978b), que contém uma palestra sua, proferida no Senado acerca da estratégia de "descompreensão política". É razoável pensar que esse autor, bem como outros intelectuais do país, a partir do contexto da "abertura lenta, gradual e segura" promovida por Geisel, se apresentasse como estudioso especializado e como intelectual público compromissado com a redemocratização do Brasil. Nesse sentido, alguns textos desse período diagnosticavam que, em função do processo de modernização levado a cabo pelos militares, o país se transformara profundamente entre 1960 e 1980.

No capítulo de uma obra que reunia alguns cientistas sociais brasileiros, WGS anunciava "A pós-revolução brasileira": as condições sociais brasileiras nos anos 1980 eram bastante distintas das condições que precederam o golpe de 1964, bem como seriam os resultados políticos desses dois processos. A ordem da cidadania regulada estava sendo contestada. Avaliando os vinte anos de militarismo no Brasil, ele afirma que os chefes de governo do período foram responsáveis por um processo de modernização conservadora, gerando várias consequências inesperadas. Embora não possa ser atribuído apenas aos militares, o fato é que, até 1984, o país havia passado por um processo de urbanização, industrialização e crescimento econômico, deixando de ser uma sociedade tradicional, marcada pelo "compadrio" e pelo "clientelismo" para tornar-se uma sociedade "aberta, porosa e fluida" (Santos, 1985: 255). 0 autor destaca então o crescimento de associações comunitárias, o maior número de greves 
no país, a sindicalização dos trabalhadores do campo, um maior número de organizações profissionais e empresariais e a formação de uma nova classe média estatal, evidenciando o anacronismo do sistema autoritário.

0 quinto e último aspecto relevante dessa segunda fase do pensamento de WGS refere-se à sua adesão declarada à democracia, embora a própria democracia ainda não constituísse objeto de discussão sistemática por parte do autor. Nos textos do primeiro período, esse compromisso já existia, mas sempre ao lado da crítica de orientação marxista acerca dos limites da democracia liberal. Democratizar o país, nos textos da segunda fase, estabelecia-se já em um imperativo normativo para WGS.

Uma terceira e última fase da sua obra, compreendida pelo período 1990-2019 (quando o autor falece), é caracterizada pela discussão da democracia brasileira, seus avanços e impasses, e do descompasso entre os ganhos institucionais e os atrasos sociais. Em Razões da desordem (Santos, 1993), por exemplo, WGS diz que o Brasil parecia ter superado de fato 0 interregno autoritário, consolidando, aqui, uma sociedade civil complexa e com eleições regulares, idôneas e competitivas. A esses traços evidentes de modernização, restava, no entanto, explicar por que a democracia brasileira não funcionava adequadamente. Ao contrário do que dizia a quase totalidade dos analistas àquela época, WGS compreendia que o problema não estava propriamente nas instituições políticas, mas na falta de cultura cívica. Contra também os que diagnosticavam uma crise de governabilidade nos anos 1990 (e defendiam, pois, uma reforma do Estado), o autor apresentava outra explicação para a dificuldade governativa brasileira. Para ele, o principal dilema da Nova República consistia num "híbrido institucional" aqui instaurado: por um lado, "uma morfologia poliárquica, excessivamente legisladora e regulatória" e, por outro, um "hobbesianismo social pré-participatório e estatofóbico" (Santos, 1993: 79). Como em um estado de natureza, a fragilidade das normas de convivência produz desconfiança generalizada, prevalecendo, então, os códigos privados de comportamento. 0 resultado desse estado de natureza é uma "cultura cívica predatória", com um padrão de interação social de soma zero, quando bem-sucedida, ou de soma negativa, quando fracassada. Não eram, portanto, as reformas políticas (tais como a do parlamentarismo, muito acalentada nos anos 1980 e 1990, ou a do voto distrital, defendida mais recentemente) que iriam resolver os principais problemas da sociedade brasileira. Muito ao contrário: elas poderiam gerar efeitos imprevistos por muitos, ainda que antevistos pelos grupos que viam seus privilégios ameaçados com a democratização da sociedade brasileira, como denuncia o autor em Regresso (Santos, 1994). Rotatividade e intensa disputa para os cargos eletivos, elevadíssima inclusão político-eleitoral (com a retirada das barreiras que impediam o voto dos pobres, mulheres, iletrados, e com a incorporação na polis do demos das regiões Norte, Nordeste e 
Centro-Oeste), entre outros fatores, compunham o que ele chamava de "expansão cívica", processo que teria rompido definitivamente com a cidadania regulada e com o padrão oligárquico de reserva de poder, prevalecente na história do Brasil republicano.

Feita a apresentação do conjunto da obra de WGS, passemos à análise de Cidadania e justiça e de outros textos nos quais se discute a cidadania regulada.

\section{O CONCEITO DE CIDADANIA REGULADA E A ERA VARGAS}

- m Cidadania e justiça, WGS avalia os impactos diferenciais dos esforços do regime pós1964 em implementar reformas nas políticas sociais. Reconstruindo historicamente a legislação brasileira sobre política social, WGS afirma que no século XIX reinava uma total ausência de leis sobre proteção social, combinada, em compensação, a um princípio laissez-fairiano de não regulamentação das profissões. 0 Estado brasileiro, como boa parte dos países à época, mantinha-se reticente no tocante à intervenção do poder público nos processos acumulativos.

Com a Revolução de 1930, inaugura-se uma nova ordem na política brasileira que permaneceria até a década de 1980, a saber: a ordem ou a cidadania regulada. 0 Estado brasileiro começa, então, a interferir diretamente na esfera da produção e na questão social. Se isso significou, por um lado, um avanço em comparação ao vácuo institucional anterior (uma vez que a criação de vários direitos trabalhistas coibiu os excessos do processo de produção), por outro lado, reforçou a possibilidade de o Estado conter as pressões do operariado (domesticando, assim, seus sindicatos mais combativos). Em certo sentido, as relações de trabalho que se resolviam privadamente passaram agora a ser reguladas e decididas pelo aparato estatal. A legislação trabalhista passava a premiar aqueles segmentos inseridos na ordem regulada por meio de incentivos e benefícios sociais, punindo, ao mesmo tempo, aqueles trabalhadores e organizações sindicais não regularizados e não inseridos no novo marco institucional. 0 aspecto determinante seria a vinculação das políticas sociais, concernentes ao problema da equidade, ao processo de acumulação:

Por cidadania regulada entendo o conceito de cidadania cujas raízes encontram-se, não em um código de valores políticos, mas em um sistema de estratificação ocupacional, e que ademais, tal sistema de estratificação ocupacional é definido por norma legal. Em outras palavras, são cidadãos todos aqueles membros da comunidade que se encontram localizados em qualquer uma das ocupações reconhecidas e definidas em lei (Santos, 1979: 75, grifos do autor).

Isso significou que o reconhecimento da cidadania dependia do reconhecimento formal por parte do Estado da profissão exercida pelo indivíduo. Todos que exerciam profissões 
não reconhecidas por lei, como os trabalhadores rurais e domésticos, tornaram-se pré-cidadãos, criando, assim, barreiras à entrada na arena política e estimulando um comportamento de submissão política ante o Estado.

Ao considerar o estado social da nação após o golpe de 1964, WGS demonstra que as desigualdades sociais entre regiões aumentaram substantivamente e revelaram também ser cumulativas, haja vista que uma região ou um indivíduo carente de um recurso normalmente é carente dos demais. Assim, apesar de avanços específicos na política social (como a criação do Fundo de Assistência ao Trabalhador Rural (FUNRURAL), que estendeu aos trabalhadores do campo o sistema previdenciário), WGS é categórico em afirmar que a política social dos militares não alterou, em essência, a ordem regulada dos anos 1930, mantendo-se a cidadania "destituída de qualquer conotação pública e universal" (Santos, 1979: 104).

Em texto posterior, WGS pondera que, desde a Revolução de 1930, a justiça ficou submetida, por meio da "obediência aos princípios integradores da cidadania regulada", à "maximização da eficiência do mercado" (Santos, 1981: 183). Diz ele: "Nenhum governo pós-45 tomou qualquer iniciativa mais consistente e sistemática no sentido de alterar os princípios da cidadania regulada e da obediência à eficiência do mercado econômico" (Santos, 1981: 183). Nesse sentido, medidas como a Lei nº 4.725 (1965), sobre a fixação dos salários profissionais e o piso salarial, e o estabelecimento do Fundo de Garantia por Tempo de Serviço (FGTS) violavam os princípios da justiça procedural. Em contrapartida, iniciativas como 0 Programa de Integração Social/Programa de Formação do Patrimônio do Servidor Público (PIS/ PASEP) e o FUNRURAL operavam segundo uma forma diversa da lógica da ordem regulada, na medida em que desvinculavam os benefícios dos azares de cada indivíduo de melhor se alocar no mercado. Criado em 1963, mas viabilizado apenas em 1971, o FUNRURAL ainda se diferenciava dos seguros sociais por não ser uma arrecadação tripartite, ficando os trabalhadores do campo dispensados de contribuir com a previdência. Essa orientação redistributiva também comparecia no PIS/PASEP, criado em 1970, uma vez que o beneficiário não precisava contribuir para o fundo que o beneficiaria. Relativizado o efeito contributivo-corporativo desses benefícios, tais políticas mantinham-se, no entanto, bem distantes da equidade universal que o conceito de cidadania regulada almejava alcançar. Desse modo, tais iniciativas não representavam para WGS uma ruptura significativa da ditadura civil-militar com a cidadania regulada, que, no geral, mantinha preservada sua estrutura:

Como dissemos anteriormente, todas as características fundamentais da ordem regulada produzida pela iniciativa pós-30 permanecem em vigor, por exemplo, a legislação sindical e previdenciária. Os extensos controles promulgados pelo Estado brasileiro pós-30 sobre o movimento sindical permanecem em vigência, assim como permanecem em operação os princípios da legis- 
lação previdenciária que fazem os benefícios da previdência social, com exceção da assistência médica, proporcionais à contribuição passada, sendo esta uma função do salário percebido (Santos, 1981: 184-185).

Confirmava-se, ademais, um padrão da política nacional: a associação entre política social e autoritarismo. Como parte de uma estratégia política, o regime repetia a política do Estado Novo de conceder direitos sociais como compensação pela restrição dos direitos políticos e como meio de aquiescência das massas insatisfeitas, ausentes nos processos de formulação das políticas públicas. 0 golpe de 1964 é interpretado como um momento de conflito entre a ordem regulada e a democracia eleitoral:

Após pouco menos de 20 anos de prática de democracia relativa, esta revelou-se incompatível com uma ordem de cidadania regulada. Por esta ou aquela razão, os diversos grupos sociais foram incapazes de contratar novas formas institucionais de administrar o processo de acumulação, por um lado, e os parâmetros de equidade, por outro. Dada a resistência da ordem conservadora da cidadania regulada, o conflito resolveu-se pelo rompimento da democracia limitada. No contexto do presente estudo, tal é o significado do movimento militar de 1964 (Santos, 1979: 82).

Com a cidadania regulada, consagrou-se a desigualdade no acesso às políticas sociais, na medida em que se vincularam os benefícios sociais às contribuições passadas e ao salário recebido, de modo que, quem era mais bem remunerado, tinha mais benefícios. Por meio desse arranjo institucional, o Estado brasileiro pôde dar uma solução eficaz ao problema da regulação da esfera da produção: criou-se uma política que, por um lado, evitava a exacerbação das iniquidades sociais (impedindo que elas se tornassem uma ameaça à ordem) e, por outro lado, embora se propusesse uma política de equidade, não comprometia, todavia, o processo de acumulação capitalista em relação ao qual o próprio Estado é dependente.

0 caso brasileiro sugere, destarte, uma via complexa de modernização, na qual as identidades políticas são formadas sem a mediação dos partidos e antes mesmo da constituição de uma ordem propriamente liberal, de modo que os atores envolvidos no conflito distributivo procuram vocalizar suas demandas não por meio da participação e da competição partidária, mas pela influência direta sobre parte da burocracia estatal, que arbitra a disputa. Esse processo produziu três consequências perversas, diz WGS. Em primeiro lugar, a submissão do operariado em relação à burocracia estatal. Em segundo lugar, a irrelevância dos partidos políticos, instituições fundamentais nas democracias. Nesse caso, o "corporativismo subdesenvolvido", padrão político no qual o conflito social está dissociado do processo partidário, dificulta a criação de "um sistema bem desenvolvido de segurança mútua" (Dahl, 2005, p. 53-54), fundamental para o funcionamento democrático, na medida em que essas 
garantias estabilizam o sistema político. A terceira consequência é a própria utilização das políticas sociais a fim de compensar a participação limitada e a baixa competitividade política. Se, no caso de muitos países do capitalismo central, como descrito no livro clássico de T. S. Marshall (1967), os direitos sociais contribuíram para uma maior integração política, no Brasil, significaram mais um obstáculo à institucionalização política.

Sem menosprezar essas consequências nocivas, WGS via ceticamente aqueles que prometiam uma modernidade ao país, no fim do século XX, por fazer ruir o legado da Era Vargas, sob a justificativa de ele ser corrupto, clientelista etc. Ao contrário, para Santos, era imprescindível expandir o Estado mínimo brasileiro, isto é, os direitos fundamentais à cidadania.

Apesar de ter gerado a cidadania regulada, o varguismo resolveu quase ao mesmo tempo dois dilemas fundamentais da ordem social moderna, a redistribuição das riquezas e a ampliação da participação política, dilemas, em geral, solucionados aos poucos. A maior dificuldade em se solucionar concomitantemente os problemas da integração nacional, da participação política e da redistribuição é que a criação de uma ordem liberal promoveria a continuação do domínio exclusivo dos oligarcas, como ocorria na Primeira República, como denunciara Oliveira Vianna (Santos, 1978a). Assim, a via da modernização clássica, iniciando-se pela integração nacional, seguida da ampliação da participação política e, por fim, da redistribuição (sequência adotada pelos países desenvolvidos), não foi possível para o Brasil. A esse respeito, WGS formulara a influente interpretação de Oliveira Vianna, para quem, na ausência de um sistema partidário liberal competitivo no país, a intervenção autoritária do Estado sobre a sociedade seria um recurso instrumental à transição "mais rápida [...] a uma sociedade liberal" (Santos, 1978a: 102-103). Essa associação entre o conceito de cidadania regulada e sua condição autoritária instrumental posicionava Vianna a meio caminho dos autoritários integralistas e da tradição liberal doutrinária brasileira.

Mesmo considerando as heranças negativas do varguismo na política nacional, como o corporativismo subdesenvolvido, a cidadania regulada e o autoritarismo, WGS conclui que essa tradição criou condições mínimas para o surgimento da democracia brasileira, institucionalizando gradualmente a competição política e incluindo politicamente setores antes marginalizados. Quando o número de competidores é restrito e o eleitorado, em sua maioria, vive na zona rural, ele se encontra basicamente dependente dos clãs familiares que competem nas eleições, como denunciara Vianna. À medida que ele se expande e passa a residir nas cidades, tornando o eleitor um anônimo, a dinâmica oligárquica acaba.

Em síntese, quando se considera toda a produção científica de WGS, percebe-se que a discussão sobre a cidadania regulada se situa em um momento específico do seu pensamento, aqui denominado de segunda fase. Embora não tenha sido um conceito negado pelo 
autor posteriormente, não foi utilizado por ele com frequência. Em uma coletânea de textos, Décadas de espanto e uma apologia democrática (Santos, 1998), WGS reúne ao fim do livro de 1998 três capítulos (1, 2 e 4) de Cidadania e justiça. Ao fim dele, redige uma "notícia bibliográfica" na qual justifica que, passados vinte anos da publicação de Cidadania e justiça, seria necessário aprofundar a pesquisa sobre a evolução das políticas sociais no país, o que 0 levou a não autorizar uma quinta edição desse livro que já se tornara um clássico do pensamento político brasileiro.

\section{CRÍTICAS E USOS DO CONCEITO DE CIDADANIA REGULADA NA INTERPRETAÇÃO DA COSMOLOGIA VARGUISTA}

esta seção, analisaremos inicialmente alguns textos que se propõem avaliar critica-
mente o livro Cidadania e justiça. Em seguida a esses primeiros textos de crítica, passaremos à análise de outros trabalhos que se apropriam do conceito de cidadania regulada.

Maria Kerbauy (1980: 165) foi quem resenhou pela primeira vez o livro supramencionado, entendendo-o como "uma contribuição extremamente significativa para as políticas públicas, dado não apenas ao crescente interesse entre os cientistas políticos pelo tema, como também ao incipiente desenvolvimento do mesmo no Brasil". A autora salienta o ganho analítico obtido por meio do conceito de cidadania regulada, como instrumento de análise das políticas sociais do regime militar. Para ela, a comparação entre os períodos de 1930-64 e de 1964-79 revela mais descontinuidade do que permanência: "A dimensão política da cidadania entra em recesso, com a violação da ordem democrática de 1964" (Kerbauy, 1980: 167). Além disso, ela nota que, segundo WGS, como não há uma teoria elaborada a respeito de política social no Brasil e como a análise desse tipo de fenômeno envolve um conjunto grande de dificuldades, a abertura democrática configurava uma necessidade moral para a análise científica da justiça social brasileira.

A segunda resenha que Cidadania e justiça recebeu é de autoria de Luciano Oliveira (1981). 0 texto reitera o caráter laudatório do escrito e os pontos destacados por Kerbauy (1980), compreendendo que, além da obra ser "útil para se pensar a crise atual da previdência", é também "estimulante para se continuar a luta pela abertura política" (Oliveira, 1981: 121). Contudo, o mérito da obra, na sua opinião, é ter formulado um conjunto de definições e de distinções que ajudariam a compreender questões prementes de sua época, como as relativas às ações destinadas à acumulação de riquezas, às compensatórias (que objetivam minorar problemas sociais decorrentes da acumulação) e às redistributivas (orientadas para 
redistribuição de renda e outros benefícios). Tanto pela resenha de Oliveira (1981) quanto pela de Kerbauy (1980), percebe-se que o livro foi compreendido à época como um escrito inovador — no campo de estudos sobre política pública — e que serviu como instrumento de crítica às políticas sociais e à própria natureza repressiva do regime militar.

O artigo de Fábio Wanderley Reis (1991), "O tabelão e a lupa", avalia criticamente a ideia proposta por WGS, situando-a como exemplo típico das deficiências presentes nas ciências sociais brasileiras. Primeiramente, a proposta de adjetivar a cidadania como regulada pressuporia alguma forma de cidadania alternativa, outro tipo de prescrição de direitos e deveres sem regulação estatal (o que, na opinião de Reis, é precisamente o contrário do que ocorreu ao longo da história). Em segundo lugar, o texto de WGS tomaria por idiossincrático "o mecanismo ocupacionalmente estratificante [...] que corresponde à categoria do seguro social" (Reis, 1991: s.p.), de acordo com o qual os benefícios são calculados em proporção à contribuição dada por cada segurado, o que ocorre em qualquer democracia. Em terceiro lugar, Reis (1991) avalia que o livro confunde os planos descritivo/explicativo com o normativo, ou seja, a tarefa de analisar objetivamente um caso concreto de construção de direitos e deveres com a tarefa de denunciar a cidadania regulada pelo Estado brasileiro (e que consagraria diferenças oriundas do mercado). Em quarto lugar, Reis (1991) assegura que historicamente 0 Brasil não é um caso excepcional de combinação entre autoritarismo e promoção de políticas sociais, como demonstra, por exemplo, a experiência alemã sob o comando de Bismark. Por fim, argumenta que a associação entre manipulação ideológica e dinâmica corporativa (presente na ideia de tutela sobre os trabalhadores e seus sindicatos) é apenas presumida, mas não propriamente comprovada por WGS.

Em texto posterior, "Cidadania democrática, corporativismo e política social no Brasil", Reis (2000) volta a polemizar com cidadania regulada, asseverando que essa categoria se fundamenta num preconceito contra as práticas corporativistas. Ao lado da ideia marshalliana da cidadania como reconhecimento de certo status de direitos do indivíduo (sobretudo por meio da distribuição dos direitos sociais), Reis (2000) assevera que o que se configurou em muitas nações foi uma espécie de mercado político, de acordo com o qual se estabelece alguns limites e soluções para o problema de conciliar democracia (igualdade) e capitalismo (acumulação). Assim, em relação à ideia de cidadania, que envolveria certa ambiguidade decorrente de se assumir um elemento comunitário (solidariedade) e outro conflituoso (interesses), o neocorporativismo teria surgido como uma solução histórica, forjando uma esfera extraparlamentar em que a burocracia passa, legitimamente, a arbitrar os conflitos entre capital e trabalho, regulando os sistemas de direitos. Trata-se de solução absolutamente comum em que o corporativismo e o Welfare State "surgem como consequência da própria dinâmica da democracia e de 
sua lógica de mercado político" (Reis, 2000: 371). Assim, o que WGS denomina de cidadania regulada, na opinião de Reis (2000: 373), nada mais é do que o "desaguadouro natural" do mercado político, do processo de desenvolvimento em que nem a opção revolucionária (fim do capitalismo), nem a opção autoritária (segundo a qual os interesses do capital se afirmariam por meio da violência) se concretizam. Reis (2000) argumenta que, contrariamente ao que é sugerido por WGS, é necessário construir um Estado de bem-estar social com algum grau de paternalismo na promoção de justiça social, e não simplesmente denunciar o corporativismo como um mal. Nas condições brasileiras, antes da emergência do cidadão, é necessário garantir a existência de clientes do Estado. Do contrário, a narrativa da cidadania regulada levar-nos-ia a imaginar a criação de uma ordem cidadã fora ou contra o Estado, ao invés de, realisticamente, apontar os caminhos para se expandir a própria regulação criticada.

Deixando de lado as críticas que a ideia de cidadania regulada recebeu, passemos à análise de algumas de suas apropriações. 0 que fica evidente é uma relativa abundância de trabalhos acadêmicos que adotam essa ideia como referencial teórico, sobretudo por meio de aplicações a contextos específicos, por exemplo: seguridade social (Teixeira, 1985), condição social dos trabalhadores rurais (Morais, 2011) e urbanos e de sua organização sindical (Jesus, 2010), políticas públicas de saúde (Sarreta, 2009) etc. ${ }^{2}$. Além dessas "aplicações" pontuais, cabe avaliar dois outros "usos" importantes desse conceito.

Primeiramente, cumpre lembrar o conhecido livro Cidadania no Brasil: o longo caminho, de José Murilo de Carvalho (2002), no qual ele destaca que, sem uma cultura republicana e com uma sociedade politicamente desmobilizada, a ordem da cidadania regulada (estabelecida a partir das políticas sociais de Vargas) produziu "um vício" nacional presente em pleno século XXI: "a tradição de maior persistência acabou sendo a que buscava melhorias por meio de aliança com o Estado, por meio de contato direto com os poderes públicos. Tal atitude seria mais bem caracterizada como 'estadania'" (Carvalho, 2002: 61). Cumpre observar que a noção de estadania salienta apenas os aspectos negativos da intervenção do Estado sobre a sociedade, (ao passo que, no conceito de cidadania regulada, a ambiguidade dessa intervenção, com seus efeitos positivos e negativos sobre a sociedade brasileira, é preservada), de modo que a reflexão de Carvalho (2002) parece se indispor mais com o tipo de aproximação entre sociedade e Estado do que em considerar se essa proximidade teria ou não favorecido a redução de desigualdades sociais.

Outro aspecto presente nos estudos que se apropriaram do conceito de cidadania regulada diz respeito à pouca valorização das inflexões políticas que ocorreram entre o Estado varguista e a dinâmica social implementada no pós-1964. A exemplo do que se pode verificar no argumento de Santos (1979), estudos influentes, como o de James Malloy (1977), voltado 
ao sistema de previdência social, e de Teixeira (1985), central à análise da reforma sanitária brasileira, identificaram um continuum teórico e político entre o chamado corporativismo populista, inaugurado nos anos 1930, e o regime burocrático-autoritário, predominante no pós-1964. Com variações de ênfase, o traço histórico invariante do período que se estende de 1930 aos anos 1970 consistiria na estratificação de direitos e na regressividade do gasto público no campo social. No caso dos trabalhos voltados à reforma sanitária, o legado da cidadania regulada, e, portanto, da própria Era Vargas, teve como entendimento síntese 0 sentido corporativo e segmentado da assistência à saúde, um obstáculo à universalização pretendida. Como parte da crítica, observava-se que nos anos 1970 esse legado corporativo, até então de corte estatizante, estaria se renovando ao favorecer o aprofundamento da oferta mercantil da atenção à saúde, propiciando elevadas taxas de acumulação de capital via estrutura médico-previdenciária pretérita.

A exemplo de James Malloy (1977), outros brasilianistas da década de 1970 produziram influentes análises acerca do processo político institucionalizado a partir de 1930. No geral, compreenderam-no como estruturas históricas duradouras de autoritarismos, estatização corporativa e patrimonialista. Trabalhos como Interest conflict and political change in Brazil, de Phillippe Schmitter (1971), Authoritarian Brazil: origins, policies, and future, de Alfred Stephan (1973), ou ainda o livro organizado por David Collier, The new authoritarianism in Latin America (1979), obtiveram forte penetração no plano nacional. Exemplos dessa influência podem ser identificados na prestigiada tese liberal da dependência, de Fernando Henrique Cardoso e Enzo Faletto (1975), e no livro Bases do autoritarismo brasileiro, de Simon Schwartzman (1982). Como observado por Santos e Guimarães (no prelo), tais intérpretes formularam, na perspectiva do liberalismo político, forte crítica à herança social varguista, pavimentando a compreensão de que a redemocratização brasileira exigia um quadro de reformas estatais direcionadas a uma franca abertura às forças e aos interesses do moderno capital estrangeiro e nacional ${ }^{3}$.

Não obstante as interpretações que tomam as cinco décadas que se seguiram à montagem do complexo corporativo institucional iniciado nos anos 1930 como um ciclo histórico resiliente, é possível localizar diversas mudanças em sua regulação político-institucional (Boschetti, 2006). Nessa arquitetura regulada da cidadania, aspectos como a participação de trabalhadores em Conselhos do Estado e a frente dos Institutos de Aposentadoria e Pensão, além da abertura ao capital privado da assistência à saúde do trabalhador (como presente no Decreto-Lei n² 200, de 1967), conformam, sem dúvida, momentos importantes das transformações introduzidas pelos governos militares. Em que pese a documentação apontando a transição de um desenho "público estatal corporativo" de direitos de cidadania para um 
modelo "corporativo privado mercantil" (Santos; Guimarães, no prelo), pós-1970, não se identificam questionamentos em torno dos usos do conceito de cidadania regulada. Isso evidencia que muitos analistas, imersos na conjuntura da redemocratização dos anos 1980, continuaram a perceber o pós-1964 como extensão das bases políticas de 1930. Por essa leitura, ainda que o golpe tenha se dado contra o maior herdeiro do varguismo, João Goulart, a intervenção militar não foi interpretada como um movimento de interdição ao ascenso de direitos que se expandiam em torno da herança getulista. Também é interessante observar que, para a geração de analistas localizados após 1964, as críticas à Era Vargas convergiam com o movimento mais amplo de descrédito das teses nacional-estatistas que guiaram o período anterior. Como aponta Juarez Guimarães (2018: 510), em um primeiro momento:

Houve quem contasse a história de 1964 como um fim inevitável e historicamente necessário de um ciclo chamado de populista ou nacional-desenvolvimentista, fruto de uma determinação econômica estrutural mais ampla do capitalismo (Immanuel Walerstein). Ou mesmo como um desfecho ineludível das contradições imanentes da aliança populista (Octávio lanni). Ou ainda, das injunções do modo de inserção do Brasil frente à dominação imperialista (em seu pluralismo, as teorias da dependência de Ruy Mauro Marini, Theotônio dos Santos e Andrew Gunder Franck). Houve quem centralizasse a explicação nas ilusões do PCB [Partido Comunista Brasileiro] em uma revolução democrática-burguesa, antifeudal e anti-imperialista, que levariam a uma expectativa frustrada de um posicionamento nacionalista da burguesia brasileira (Caio Prado Júnior).

Em seu sentido comum, tais explicações seriam verdades parciais, ocupadas em localizar os motivos da interrupção à republicanização democrática brasileira. Com o passar do tempo, as apreciações acerca do legado varguista apresentaram significativas variações, e, na entrada para a década de 1990, distintas reflexões da experiência sociopolítica pré-1964 começaram a ganhar espaço. Trabalhos como os de Jorge Ferreira (2001) e Lucília Neves (2001) expandiram a compreensão das lutas forjadas entre 1946 e 1964, trazendo à tona uma refinada compreensão das agendas do Partido Comunista Brasileiro (PCB) e do Partido Trabalhista Brasileiro (PTB), suas correntes internas, lideranças e vínculos com movimentos sindicais.

Avançando nessa chave interpretativa, ou seja, na valorização de uma história social da formação dos direitos na chamada Era Vargas, Ângela Gomes (1988) repõe a noção de trabalhismo em contraponto à difundida expressão do populismo utilizada para caracterizar a experiência social pós-1930. Temas correlacionados à condição regulada da cidadania varguista, como cooptação e manipulação, seriam confrontados com investigações que revelariam feições da palavra operária talhadas ao longo das primeiras décadas do século XX. Nesse sentido, uma polêmica que se estabeleceria em relação à formulação e aos usos da 
cidadania regulada de WGS seria o lugar que a participação popular e trabalhista assumiria na história republicana brasileira, contestando sua redução a uma dimensão menor nesse processo. Com A invenção do trabalhismo ${ }^{4}$, Gomes (1988) desloca as conclusões unilateralmente depreciativas que acompanham a reafirmação dos direitos sociais no Brasil, abrindo outro sentido interpretativo para a herança social e sindical varguista, como a Justiça do Trabalho e a Consolidação das Leis do Trabalho (CLT). As forças sociais que se organizaram em torno do projeto democrático anunciado pelo nacional-desenvolvimentista, vigente de 1946 a 1964, não seriam um apêndice da propalada república populista. Adotando a perspectiva da história social, Gomes (1988) documentaria que a Justiça do Trabalho e o corpo de direitos estruturados na CLT podiam evidenciar antes a institucionalização de bandeiras operárias que a pura cooptação dos segmentos populares.

Em trabalho mais recente, Adalberto Cardoso (2010) procurou solucionar o enigma das persistentes desigualdades brasileiras e o papel da Era Vargas em relação a elas. Segundo ele, o projeto varguista de cidadania regulada representou para os trabalhadores uma esperança de inclusão na ordem nacional e um momento fundamental para a construção de um Estado de bem-estar brasileiro. A cidadania regulada constituiu historicamente uma promessa inédita de inclusão social que, na medida em que impactou as expectativas dos atores sociais, trouxe também consequências para a sociabilidade capitalista em formação. Cardoso (2010) pondera que o grande ganho analítico desse conceito foi reconhecer a cidadania como um processo em aberto, de acordo com o qual se o indivíduo tivesse sua profissão reconhecida, passava a ter o status de cidadão. Curioso notar que o argumento desse autor destoa parcialmente do de WGS, pois, enquanto este pensava a cidadania como possibilidade (de inclusão e exclusão), aquele o compreende como promessa. Para Cardoso, a cidadania regulada não criou uma divisão clara entre incluídos e excluídos, mas um continuum que fazia da inclusão uma promessa para o trabalhador brasileiro, a depender do seu grau de carências de recursos. Além de um continuum, a cidadania regulada representava também uma possibilidade real de direito: se antes da década de 1930 a conquista de direitos esbarrava na Constituição de 1891, para a qual a interferência estatal na questão social era ilegítima, a partir da Era Vargas, para ser cidadão, bastava ao trabalhador brasileiro encontrar os meios para ser reconhecido pelo Estado. Assim, independentemente de ter sido ou não outorgada, disjunção que organizou o debate nas ciências sociais, "fato é que [...] a legislação social foi apropriada pelos trabalhadores, e a "cidadania regulada" não era outra coisa senão o modo dessa apropriação em seu processo mais miúdo, mais cotidiano" (Cardoso, 2010: 791-792, grifo do original). Sua avaliação reconhece um potencial cívico na cidadania regulada que gerou, entre outros efeitos, um gigantesco fluxo migratório do 
campo rumo às cidades, como decorrência da "atratividade dos direitos", bem como a expectativa de acesso a melhores serviços públicos de saúde, educação e aposentadoria (Cardoso, 2010: 795). Esses direitos assegurados pela ordem regulada passaram a valer como um mínimo civilizatório, um parâmetro para avaliar qualquer contrato de trabalho, até mesmo no mercado informal.

Em boa medida, a força dessas interpretações desloca o cânone explicativo das ciências sociais no Brasil acerca da chamada Era Vargas, permitindo-nos concluir que existem pelo menos duas grandes tradições interpretativas em torno de categorias como populismo, trabalhismo, desenvolvimentismo e nacionalismo. No vértice dessas tradições, o conceito de cidadania regulada ocupa, como vimos, uma condição reveladora da complexidade do chamado varguismo. Destarte, o conceito de cidadania regulada, desde que foi apresentado, há mais de quarenta anos, foi razoavelmente incorporado como uma narrativa plausível acerca da construção da ordem social brasileira. Mais do que ter suscitado críticas mais diretas (com exceção dos artigos de Reis), ele parece ter servido, em um primeiro momento, como marco teórico para localizar os limites da formação sociopolítica brasileira de se inserir no almejado mundo democrático. Já nos anos 1990, talvez mesmo por configurar um momento agudo de desconstrução aberta das instituições fundadas na ordem varguista, além do distanciamento histórico em relação ao regime de 1964, o eixo analítico tornou-se mais atento à complexidade política do período. De todo modo, ante os desafios do tempo presente, parece plausível sustentar que, como categoria de análise, a cidadania regulada não parece ter esgotado sua contribuição histórica à problematização da Era Vargas. Precisamente porque o próprio legado varguista se encontra, mais que nunca, em franco processo de disputa de sentidos.

Talvez o grande potencial analítico do conceito de cidadania regulada seja preservar a ambiguidade do processo histórico brasileiro, segundo o qual ganhos do ponto de vista cívico não excluíram certas perdas, particularmente no que tange à limitação do sindicalismo e ao processo de consolidação do sistema partidário brasileiro. Ao acompanhar a fortuna crítica de cidadania regulada nos vários caminhos interpretativos do pensamento político brasileiro, compreende-se que a Era Vargas diz mais do que um momento de fundação da ordem social, política, econômica e institucional brasileira. Sua força consiste em nortear por gerações, e prossegue na atualidade, as expectativas normativas do que venha a ser reconhecido no disputado sentido da democracia brasileira. Ao que tudo indica, esse passado continuará lançando a sombra do seu voo sobre a ventura política brasiliana, em que a reposição inusitada de desafios clássicos ficará ao encargo das reflexões atentas no futuro que se abre. 


\section{NOTAS}

1 Cumpre aqui uma pequena digressão: como nota Renato Lessa (2010), ao contrário da ciência política estadunidense que, no seu contexto de fundação, convivia em seu país com uma (ou algo próximo a uma) democracia eleitoral de massas, no Brasil, os founding fathers da moderna ciência política vivenciavam aqui uma autocracia, o que ajuda a compreender a relevância dessa temática na intelectualidade do período.

2 Esses trabalhos foram identificados por meio de sistema de busca do site Biblioteca Eletrônica Científica Online (SciELO), que também sugere outros estudos que usam esse conceito.

3 A importância das análises neocorporativistas para interpretar o legado varguista, como se propõe o conceito de cidadania regulada de WGS, pode ser localizada em (Santos e Guimarães, no prelo).

4 Primeira tese de doutorado defendida no Instituto Universitário de Pesquisas do Rio de Janeiro (IUPERJ) e orientada, é importante frisar, por WGS.

\section{REFERÊNCIAS BIBLIOGRÁFICAS}

BOSCHETTI, Ivanete. Seguridade social e trabalho: paradoxos na construção das políticas de previdência e assistência social. Brasília: UnB; Letras Livres, 2006.

CARDOSO, Adalberto. Uma utopia brasileira: Vargas e a construção do Estado de Bem-Estar numa sociedade estruturalmente desigual. Dados, Rio de Janeiro, v. 53, n. 4, p. 775-819, 2010. https://doi.org/10.1590/ S0011-52582010000400001

CARDOSO, Fernando Henrique; FALETTO, Enzo. Dependência e desenvolvimento na América Latina: ensaios de interpretação sociológica. 4. ed. Rio de Janeiro: Zahar, 1975.

CARVALHO, José Murilo de. Cidadania no Brasil: o longo caminho. 3. ed. Rio de Janeiro: Civilização Brasileira, 2002.

COLLIER, David (org.) The new authoritarianism in Latin America. Princeton: Princeton University Press, 1979.

DAHL, Robert. Poliarquia: participação e oposição. São Paulo: Edusp, 2005.

FERREIRA, Jorge. 0 nome e a coisa: o populismo na política brasileira. In: FERREIRA, J. (org.). 0 populismo e sua história: debate e crítica. Rio de Janeiro: Civilização Brasileira, 2001. p. 167-203.

GOMES, Ângela. A invenção do trabalhismo. São Paulo: Vértice, 1988.

GUIMARÃES, Juarez. A Contra-Revolução Neoliberal e o Desafio Socialista da Refundação da República Democrática no Brasil. In: HORTA, C. R.; COSTA, C.; ALVES, F. Novos contextos e desafios do mundo do trabalho. Belo Horizonte: Fino Traço, 2018. p. 507-527.

JESUS, Selma. Da cidadania regulada à cidadania regressiva: um estudo de caso do projeto de corporativismo urbano da CUT. Tese (Doutorado) - Universidade Federal da Bahia, Salvador, 2010. 
KERBAUY, Maria Tereza. Resenhas. Perspectivas, São Paulo, v. 3, p. 165-168, 1980.

LESSA, Renato. 0 campo da Ciência Política no Brasil: uma aproximaç̧ão construtivista. In: Martins, Carlos Benedito (org.). Horizontes das Ciências Sociais no Brasil. São Paulo: ANPOCS, 2010.

LYNCH, Christian. A institucionalização da área do pensamento político brasileiro no âmbito das ciências sociais: revisitando a pesquisa de Wanderley Guilherme dos Santos (1963-1978). In: DULCl, Otavio (org.). Leituras críticas sobre Wanderley Guilherme dos Santos. Belo Horizonte; São Paulo: Ed. UFMG; Ed. Fundação Perseu Abramo, 2013. p-36-60.

MALLOY, James. The Authoritarianism and Corporatism in Latin America: the modal pattern. In: MALLOY, J. (org.) Authoritarianism and corporatism in Latin America. Pittsburgh: Pittsburgh University Press, 1977.

MARSHALL, Thomas. Cidadania, classe social e status. Rio de Janeiro: Zahar, 1967.

MORAIS, Michelle. Trabalhadores rurais e cidadania no Brasil (1930-1964). Em tempo de histórias, Brasília, n. 19, p. 16-35, 2011. https://doi.org/10.26512/emtempos.v0i19.19879

MOREIRA, Marcelo. O pensamento político de Wanderley Guilherme dos Santos. Belo Horizonte: Appris, 2020. (no prelo.)

NEVES, Lucília de Almeida. Trabalhismo, nacionalismo e desenvolvimentismo: um projeto para o Brasil (1945 a 1964). In: FERREIRA, J. (org.). O populismo e sua história: debate e crítica. Rio de Janeiro: Civilização Brasileira, 2001. p. 167-204.

OLIVEIRA, Luciano. Recensões. Ciência \& Trópico, Recife, v. 9, n. 1, 1981.

REIS, Fábio Wanderley. Cidadania democrática, corporativismo e política social no Brasil. In: REIS, Fábio Wanderley. Mercado e utopia: teoria política e sociedade brasileira. São Paulo: Edusp, 2000. p. 359-386.

REIS, Fábio Wanderley. 0 tabelão e a lupa: teoria, método generalizante e idiografia no contexto brasileiro. Revista Brasileira de Ciências Sociais, São Paulo, v. 6, n. 16, 1991.

SANTOS, Ronaldo; GUIMARÃES, Juarez. Aventuras do corporativismo liberal: da desconstrução da herança varguista à destruição do público. In: VANUCCHI, Marco et al. (orgs.). Corporativismo: ideias e práticas. Salvador: SAGGA. p. 147-167. (no prelo.)

SANTOS, Wanderley Guilherme dos. A pós-revolução brasileira. In: JAGUARIBE, H. et al. Brasil: Sociedade Democrática. Rio de Janeiro: José Olympio, 1985. p. 223-336.

SANTOS, Wanderley Guilherme dos. Cidadania e justiça: a política social na ordem brasileira. Rio de Janeiro: Campus, 1979.

SANTOS, Wanderley Guilherme dos. Décadas de espanto e uma apologia democrática. Rio de Janeiro: Rocco, 1998.

SANTOS, Wanderley Guilherme dos. Introdução ao estudo das contradições sociais no Brasil. Rio de Janeiro: ISEB, 1963.

SANTOS, Wanderley Guilherme dos. Ordem burguesa e liberalismo político. São Paulo: Duas Cidades, 1978a.

SANTOS, Wanderley Guilherme dos. Poder e política: crônica do autoritarismo brasileiro. Rio de Janeiro: Forense Universitária, 1978b. 
SANTOS, Wanderley Guilherme dos. Quem dará o golpe no Brasil? Rio de Janeiro: Civilização Brasileira, 1962.

SANTOS, Wanderley Guilherme dos. Razões da desordem. Rio de Janeiro: Rocco, 1993.

SANTOS, Wanderley Guilherme dos. Regresso: máscaras institucionais do liberalismo oligárquico. Rio de Janeiro: Opera Nostra, 1994.

SANTOS, Wanderley Guilherme dos. Sessenta e quatro: anatomia da crise. São Paulo: Vértice, 1986.

SARRETA, Fernanda. Educação permanente em saúde para os trabalhadores do SUS [online]. São Paulo: Editora UNESP; São Paulo: Cultura Acadêmica, 2009.

SCHMITTER, Phillippe. Interest Conflict and Political Change in Brazil. Stanford: Stanford University Press, 1971.

SCHWARTZMAN, Simon. Bases do autoritarismo brasileiro. 2. ed. Rio de Janeiro: Campus, 1982.

STEPHAN, Alfred C. Authoritarian Brazil: origins, policies, and future. New Haven: Yale University Press, 1973.

TEIXEIRA, Sonia Fleury. Política social e democracia: reflexões sobre o legado da seguridade social". Cadernos de Saúde Pública, Rio de Janeiro, v. 1, n. 4, p. 400-417, 1985. https://doi.org/10.1590/S0102$311 \times 1985000400002$ 